\title{
Fertility After Ovarian Cystectomy: How Does Surgery Affect IVF/ICSI Outcomes?
}

\author{
Fertilität nach Entfernung einer Ovarialzyste: wie wirkt sich \\ der operative Eingriff auf das Outcome von IVF bzw. ICSI aus?
}

(3)(1) (요 $\ominus$

\begin{abstract}
Authors
Affiliations

1 Universitätsmedizin der Johannes Gutenberg-Universität Mainz, Klinik und Poliklinik für Geburtshilfe und Frauengesundheit, Mainz, Germany

2 Kinderwunschzentrum Wiesbaden, Wiesbaden, Germany

3 IMBEI-Institut für Medizinische Biometrie, Epidemiologie und Informatik, Universitätsmedizin der Johannes Gutenberg-Universität Mainz, Mainz, Germany
\end{abstract}

Ruth Gomez ${ }^{1}$, Martin Schorsch ${ }^{2}$, Aslihan Gerhold-Ay ${ }^{3}$, Annette Hasenburg ${ }^{1}$, Rudolf Seufert ${ }^{1}$, Christine Skala

Key words

ovarian cyst, IVF/ICSI, clinical pregnancy rates, fertilization rate, oocyte number

Schlüsselwörter

Ovarialzyste, IVF/ICSI, klinische Schwangerschaftsrate, Befruchtungsrate, Oozytenzahl

received 9.2.2018

revised 20.9.2018

accepted 19.10 .2018

\section{Bibliography}

DOI https://doi.org/10.1055/a-0767-6722

Geburtsh Frauenheilk 2019; 79: 72-78 @ Georg Thieme Verlag KG Stuttgart · New York | ISSN 0016-5751

\section{Correspondence}

Dr. med. Ruth Gomez

Kinderwunschzentrum der Universitätsmedizin

der Johannes Gutenberg Universität Mainz

Langenbeckstraße 1, 55131 Mainz, Germany

rgomez195@gmail.com

\section{ABSTRACT}

Introduction For patients considering undergoing assisted reproductive techniques (ART), many concerns arise when persistent ovarian cysts are found. This large study aimed to determine how ovarian cyst removal affects success rates of IVF/ICSI therapies.
Methods 550 patients who underwent an IVF/ICSI treatment between 2002 and 2011 with a persistent ovarian cyst $\leq 5 \mathrm{~cm}$ before treatment were analyzed retrospectively. 328 patients' preference was to undergo a laparoscopic cystectomy and 222 patients opted for a conservative management. Control subjects included 13552 patients undergoing IVF/ICSI at the same period of time without an ovarian cyst.

Results After adjusting for age, patients with ovarian cysts without surgery needed a significant higher stimulation dose than the control group ( 2576.4 vs. $2207.5 \mathrm{IU}, \mathrm{p}<0.001$ ). However, on average, they had $1.13(-0.25-2.01)$ higher oocyte number retrieved compared to the operated patients $(9.0 \pm 5.5$ vs. $8.2 \pm 5.0)(p=0.012)$. Patients after surgical cyst removal had a significant lower number of oocytes retrieved (MNOR) in comparison to the control group (8.2 \pm 5.0 vs. $9.5 \pm 5.4)(p=0.00)$. Compared to controls, operated patients had similar clinical pregnancy rate (CPR) (34.2 vs. $33.5 \%$ ) OR 1.031 (95\% Cl 0.817-1.302) ( $p=0.815)$. Compared to controls, patients without surgery showed significant lower pregnancy rate (34.2 vs. 25,7\%) OR 1.428 (95\% Cl 1.054-1.936) $(p=0.002)$ and lower live birth rate (LBR) (21.9 vs. $13.5 \%)$ OR 1.685 (95\% Cl 1.143-2.485) ( $p=0.008)$.

Conclusions Ovarian cystectomy did not negatively impact the pregnancy rate or the live birth rate compared to controls.

\section{ZUSAMMENFASSUNG}

Einleitung Für Patientinnen, die sich einer Behandlung zur künstlichen Befruchtung (ART) unterziehen, stellt die Entdeckung persistierender Ovarialzysten eine Herausforderung dar. Ziel dieser breit angelegten Studie war es herauszufinden, wie sich die chirurgische Enffernung von Ovarialzysten auf die Erfolgsraten von IVF- und ICSI-Behandlungen auswirkt.

Methoden Die Daten von insgesamt 550 Patientinnen mit persistierenden Ovarialzysten (Durchmesser der Zyste vor der Behandlung $\leq 5 \mathrm{~cm}$ ), die sich zwischen 2002 und 2011 einer IVF- bzw. ICSI-Behandlung unterzogen hatten, wurden retrospektiv analysiert. 328 Patientinnen unterzogen sich einer laparoskopischen Zystektomie, während 222 Patientinnen ein konservatives Management vorzogen. Die Kontroll- 
gruppe bestand aus 13552 Patientinnen ohne Ovarialzysten, die im selben Zeitraum ebenfalls eine IVF- bzw. ICSI-Behandlung hatten.

Ergebnisse Nachdem die Daten altersbereinigt wurden, zeigte sich, dass die nicht chirurgisch behandelten Patientinnen mit ovarieller Raumforderung eine signifikant höhere Stimulationsdosis benötigten verglichen mit den Frauen der Kontrollgruppe (2576,4 vs. 2207,5 IU, p <0,001). Die Zahl gewonnener Eizellen in der nicht operierten Gruppe war mit 1,13 $(-0,25-2,01)$ höher, verglichen mit der Gruppe chirurgisch behandelter Patientinnen $(9,0 \pm 5,5$ vs. $8,2 \pm 5,0)(p=0,012)$. Bei Patientinnen, deren Zyste zuvor chirurgisch entfernt wurde, wurde eine signifikant niedrigere Zahl von Eizellen entnommen (MNOR) verglichen mit der Kontrollgruppe
$(8,2 \pm 5,0$ vs. $9,5 \pm 5,4)(p=0,00)$. Aber die klinische Schwangerschaftsrate der operierten Patientinnen unterschied sich nur unwesentlich von der Schwangerschaftsrate der Kontrollgruppe (34,2 vs. 33,5\%), OR 1,031 (95\%-KI 0,817-1,302) $(p=0,815)$. Verglichen mit der Kontrollgruppe hatten nicht operierte Patientinnen eine signifikant niedrigere Schwangerschaftsrate (34,2 vs. $25,7 \%$ ) OR 1,428 (95\%-KI 1,054-1,936) $(p=0,002)$ und eine niedrigere Lebendgeburtenrate (LBR) ( 21,9 vs. $13,5 \%)$ OR 1,685 (95\%-KI 1,143-2,485) ( $p=0,008)$. Schlussfolgerung Verglichen mit der Kontrollgruppe hat die chirurgische Entfernung einer Ovarialzyste sich nicht negativ auf die Schwangerschaftsrate oder die Lebendgeburtenrate der operierten Frauen ausgewirkt.

\section{Introduction}

As women have commonly begun opting to establish their careers before they begin having children, efforts to conceive are increasingly being postponed to later reproductive ages. Thus growing numbers of women are using ART when they are not otherwise able to conceive. Ovarian cysts are found in around $7 \%$ of premenopausal women [6] during routine screening transvaginal ultrasound.

When ovarian cysts persist, they are usually not due to cyclic changes and therefore tend not to regress. Such cysts include endometrioma, dermoid, and serous or mucinous cystadenomas.

They can affect ovarian stimulation and sometimes they grow during controlled ovarian stimulation. As ART in Germany needs a financial support from the concerned couples, initial conditions before treatment should be optimal.

Due to the risks ovarian cysts present, potential rupture or malignancy, laparoscopic cystectomy has become the gold standard in the surgical management of persistent adnexal masses [1,7]. Thus, ovarian cystectomy affects ovarian reserves $[17,23]$ and consequently ART outcomes [5, 29].

Therefore a surgical approach is not always the first choice. The IOTA criteria described by Timmerman [26] give good features to evaluate the dignity of an ovarian mass. The practicability was proofed and described in a metaanalysis by Nunes [15].

To date, most published studies on ovarian cysts only include endometriomas, meaning that other entities remain under-represented [25]. As their definitive histological type is not known at the time of diagnosis, IOTA criteria help us to determine how they are managed clinically.

This large sample study aimed to evaluate both options that patients and physicians have when persistent ovarian cysts are found before ART treatment. We purposed to analyze the impact of ovarian cyst removal versus conservative management on patients considering IVF/ICSI procedures. Using a notable control group, we tried to evaluate the impact of the cyst itself, regardless of histological type. We are specifically interested in understanding fertility consequences of ovarian surgical procedures.

\section{Material and Methods}

\section{Patients}

This is a retrospective single center cohort study. Between 2002 and 201114102 patients 18 to 40 years old underwent IVF/ICSI treatment at the fertility center Kinderwunschzentrum Wiesbaden because of female, idiopathic or male subfertility.

At the beginning of the ovarian cycle a vaginal ultrasound was performed. 13552 patients did not present any pathological finding during transvaginal ultrasound (control group). 550 patients were diagnosed with a persistent asymptomatic ovarian cyst. These ovarian masses were unsuspecting lesions according to IOTA criteria, and were $20-50 \mathrm{~mm}$. After medical examination and counseling 328 patients personally decided to undergo a conventional laparoscopic cyst extirpation (group 1), 222 patients decided not to undergo any surgery (group 2).

We analyzed the first IVF/ICSI cycle. Several parameters were documented including age, total gonadotrophin stimulation dose, stimulation time, mean number of oocytes retrieved (MNOR), fertilization rate (FR), clinical pregnancy rate (CPR). The pregnancy outcome was analyzed by the live birth rate (LBR) and miscarriage rate (MR).

\section{Treatment}

Women underwent either long agonist protocol or GnRH antagonist protocol controlled ovarian hyperstimulation. The long agonist protocol included initial down regulation with $\mathrm{GnRH}$ agonist as a depot injection during the mid-luteal phase of the previous menstrual cycle. The GnRH antagonist was initiated when the lead follicle had a diameter of 12-14 mm, usually on the 6th day of stimulation and was given daily. Recombinant FSH was started from day 2 or 3 of the cycle and dosages were calculated based on patients' age, antral follicle count (AFC), basal FSH/LH levels, and response to previous ovarian stimulation. The individual daily dose was adjusted based on follicular growth monitoring and estradiol levels in order to achieve optimal ovarian response in all patients. $10000 \mathrm{IU}$ hCG were administered subcutaneously when at least two follicles had a diameter of over $18 \mathrm{~mm}$. Oocyte retrieval was performed 36 hours later. 
Standard laboratory protocols were followed, including intracytoplasmic sperm injection. All assisted reproductive techniques were used according to the "Deutsches Embryonenschutzgesetz" (embryo protection law). Ultrasound guided transfer of one, two or, at most, three embryos was performed on day three after oocyte retrieval. All patients received a progesterone supplement during the luteal phase. Serum $\beta$-HCG level was measured fourteen days after the transfer. Pregnancy was diagnosed if serum $\beta$-HCG was at least $50 \mathrm{lU} / \mathrm{ml}$ and an ultrasound examination two weeks later confirmed the presence of a gestational sac in the uterine cavity. Phone follow-up was performed 40 weeks after embryo transfer in order to collect data about the obstetrical outcome.

\section{Statistics}

Statistical analysis was performed through Statistics Package for Social Sciences (SPSS 22.0, Chicago IL, USA).

For the descriptive analysis categorical variables were summarized as total numbers and percentages and means with standard deviations where given for continuous variables.

Median with first and third quartiles (Q1 and Q3) were given for non-normally distributed continuous variables.

The association of the outcome variable of being pregnant or not was analyzed for different continuous variables like total FSH dosis, duration of treatment, MNOR and FR using a linear model.

For categorical variables like CPR, MR and LBR we performed logistic regression models and adjusted for age. The results of the models are presented as odds ratios (ORs) with $95 \%$ confidence intervals. The analyses were performed as explorative analyses. P-values were given for descriptive reasons only, and should be interpreted in connection with the effect estimates (OR).
Ethical approval: All procedures performed in studies involving human participants were in accordance with the ethical standards of the institutional research committee and with the 1964 Helsinki declaration and its later amendments or comparable ethical standards.

\section{Results}

A total of 14102 patients who had undergone an IVF/ICSI cycle between 2002 and 2011 were analyzed. 328 patients with a persistent mass decided to perform a laparoscopic cyst extirpation and 222 patients decided not to undergo any surgery. 13552 control patients had no diagnosable ovarian cyst (see $>$ Table 1 and Fig. 1 for further baseline characteristics).

Patients were on average 33.1 years old $( \pm 4.2)$ and required a mean dose of $2217.4 \mathrm{IU}( \pm 945.5)$ of recombinant FSH for 11.1 days $( \pm 3.4)$. The mean number of oocytes retrieved was 9.5 $( \pm 5.4)$ with a fertilization rate of $62.1 \%( \pm 22.9)$. Concerning oocyte quality, a fertilization rate of $62.1 \%( \pm 22.9)$ was found. The overall clinical pregnancy rate was $34 \%$ with a miscarriage rate of $22.9 \%$. The overall live birth rate was $22.95 \%$.

\section{Age}

All of the patients were comparable in terms of age. The mean age of patients who underwent ovarian cystectomy was 33 years $( \pm 4.3)$, comparable to the mean age of those patients who did not undergo surgery ( $34 \pm 4.0$ years) and to that of the control group (33 \pm 4.2 years).

- Table 1 Results of the analysed linear regression models for age, FSH dosis, duration of treatment, mean number of oocytes retrieved (MNOR), fertilization rate (FR), clinical pregnancy rate (CPR) live birth rate (LBR) and miscarriage (MR). All models were adjusted for age.

\begin{tabular}{|c|c|c|c|c|c|}
\hline & Total & $\begin{array}{l}\text { Group 1: ovarian } \\
\text { cyst surgically } \\
\text { treated }\end{array}$ & $\begin{array}{l}\text { Group 2: intact } \\
\text { ovarian cyst }\end{array}$ & $\begin{array}{l}\text { Group 3: } \\
\text { control group }\end{array}$ & p-value \\
\hline Age (years) & $33.1 \pm 4.2$ & $33.0 \pm 4.3$ & $34.3 \pm 4.0$ & $33.1 \pm 4.2$ & n.s. \\
\hline Total dose of FSH used (IU) & $2217.4 \pm 945.5$ & $2375.6 \pm 1159.5^{*}$ & $2576.4 \pm 1269 * *$ & $2207.5 \pm 931.9^{*},{ }^{* *}$ & $\begin{array}{l}{ }^{*} \mathrm{p}=0.001 \\
{ }^{* *} \mathrm{p}<0.001\end{array}$ \\
\hline Duration of treatment (days) & $11.1 \pm 3.4$ & $11.3 \pm 4.2$ & $11.3 \pm 3.5$ & $11.1 \pm 3.4$ & n.s. \\
\hline \multirow[t]{2}{*}{$\begin{array}{l}\text { Mean number of oocytes } \\
\text { retrieved (MNOR) }\end{array}$} & $9.5 \pm 5.37$ & $8.2 \pm 5.0^{*}, * *$ & $9.0 \pm 5.5^{* *}$ & $9.5 \pm 5.4^{*}$ & ${ }^{*} p=0.00$ \\
\hline & & & & & ${ }^{* *} p=0.012$ \\
\hline Fertilization rate (FR \%) & $62.1 \pm 22.9$ & $63 \pm 23.7$ & $60.6 \pm 24.4$ & $62.1 \pm 22.8$ & n.s. \\
\hline Pregnant women & 4796 & 110 & 57 & 4629 & \\
\hline Clinical pregnancy (CPR \%) & $34 \%$ & $(33.5 \%)^{*}$ & $(25.7 \%)^{*},{ }^{* *}$ & $(34.2 \%)^{* *}$ & $\begin{array}{l}{ }^{*} p=0.062 \\
{ }^{* *} p=0.022\end{array}$ \\
\hline Deliveries & 3057 & 60 & 30 & 2967 & \\
\hline Live birth (LBR \%) & $21.70 \%$ & $18.30 \%$ & $(13.5 \%)^{*}$ & $(21.9 \%)^{*}$ & ${ }^{*} \mathrm{p}=0.008$ \\
\hline Miscarriage (MR) & $1100(22.9 \%)$ & $29(26.4 \%)$ & $16(28.1 \%)$ & $1065(23.0 \%)$ & n.s. \\
\hline Unknown pregnancy outcome & $629(4.5 \%)$ & $21(6.4 \%)$ & $11(5 \%)$ & $597(4.4 \%)$ & \\
\hline
\end{tabular}



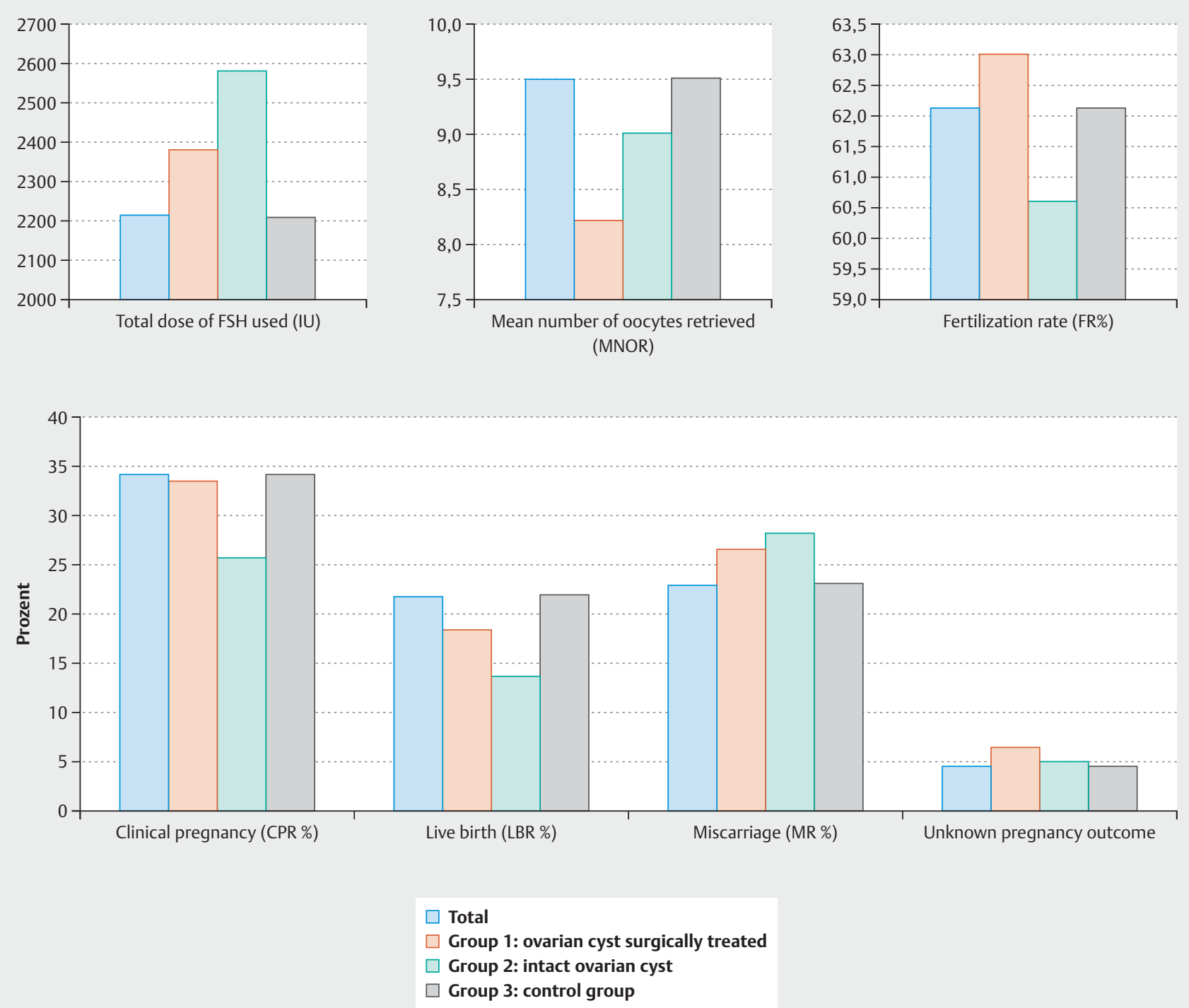

- Fig. 1 Results for FSH dosis, mean number of oocytes retrieved (MNOR), fertilization rate (FR), clinical pregnancy rate (CPR), live birth rate (LBR) and miscarriage (MR) in the three groups.

\section{Stimulation}

Patients from all groups were stimulated with comparable gonadotrophin doses for a similar time frame.

Operated patients were stimulated for 11.3 days $( \pm 4.2)$ and patients with an intact ovarian cyst were stimulated for 11.3 days $( \pm 3.5)$. Control patients were stimulated for 11.1 days $( \pm 3.4)$.

Both operated and non-operated patients with ovarian cysts (group 1 and 2) needed similar doses and required on average higher stimulation dose than the controls. Patients with an intact ovarian cyst required on average mean 113.96 IU (-88.111316.039) few more doses of gonadotrophin than the patients who had undergone ovarian cyst removal procedures, without relevance ( $2576 \pm 1269$ vs. $2376 \pm 1160 \mathrm{IU}$; $p$-value $=0.268)$.

Controls needed the lowest stimulation dose. They required on average mean 170.27 IU (-270.79 - -69.76) relevant few less doses than the cystectomy group (2208 \pm 932 vs.
$2376 \pm 1160 \mathrm{lU} ; \mathrm{p}$-value $=0.001)$ and relevant few less doses than the non operated group ( $2208 \pm 932$ vs. $2576 \pm 1269 \mathrm{IU}$; p-value $<0.001)$.

\section{Oocyte retrieval}

Concerning the mean number of oocytes retrieved (MNOR) there was a significant difference comparing both ovarian cyst groups ( $p$-value $=0.012)$. MNOR was higher in the group who did not undergo surgery ( $9 \pm 5.5$ vs. $8.2 \pm 5.0$ oocytes). Compared to controls, the surgical group (group 1) showed significant lower amount of oocytes $(9.5 \pm 5.4$ vs. $8.2 \pm 5.0$ oocytes; p-value $=0.00$ ). Patients after cystectomy (group 1 ) showed the lowest MNOR. Patients with an intact ovarian cyst and controls showed similar MNOR ( $9 \pm 5.5$ vs. $9.5 \pm 5.4$ oocytes; $p$-value $=0.39)$. 


\section{Fertilization rate (FR)}

Concerning oocyte quality, FR were similar in all groups, without statistical significance.

\section{Clinical Pregnancy Rate (CPR)}

The intact ovarian cyst group (group 2) showed the lowest chances of achieving pregnancy. When comparing no surgery (group 2) with surgery (group 1) (25.7 vs. $33.5 \%$ ) there was a reduction of $30.5 \%$ in the chance of achieving a pregnancy (OR $0.695[95 \% \mathrm{Cl}$ 0.474-1.019] p-value $=0.062$ ). The surgical group (group 1 ) and the controls showed comparable CPR (33.5 and 34.2\%, OR 1.031 [95\% Cl 0.817-1.302] p-value = 0.795). Relevant higher CPR was observed in controls than in patients with an intact ovarian cyst (34.2 vs. 25.7\%, OR 1.428 [95\% Cl 1.054-1.936] p-value =0.022).

\section{Live birth rate (LBR)}

It was possible to collect follow-up data from $94.73 \%$ of the women who became pregnant. The number of live births in women with an operated ovarian cyst, intact cyst, and no cysts were similar: 60 (18.3\%), 30 (13.5\%), and 2967 (21.9\%) respectively. Even though lower LBR in those who preferred conservative management (group 2) than after surgery was found, no statistical differences emerged (13.5 vs. 18.3\%, OR 0.71 [95\% Cl 0.439-1.148] $\mathrm{p}$-value $=0.163)$. LBR on the controls was comparable to the cystectomy group (21.9 vs. $18.3 \%$ ), OR 1.26 (95\% Cl 0.948-1.674) $\mathrm{p}$-value $=0.111$. Nevertheless relevant higher LBR was found on the controls when compared to the intact ovarian cyst group (21.9 vs. $13.5 \%$, OR 1.685 [95\% Cl 1.143-2.485] p-value $=0.008$ ).

\section{Miscarriage rate (MR)}

There were no remarkable differences among the MR. The number of miscarriages in women with operated cysts, intact ovarian cysts, and no cysts were 29 (26.4\%), 16 (28.1\%), and 1065 (23\%) respectively. No relationship was found when comparing miscarriages in the non-operated patients with operated patients (28.1 vs. $26.4 \%$, OR 1.030 [95\% Cl 0.499-2.126] p-value $=0.935$ ) or in the controls with the operated patients ( 23 vs. $26.4 \%$, OR 0.853 [95\% Cl 0.554-1.314] p-value $=0.47$ ). Likewise, no important differences were found when comparing MR in the controls with the intact ovarian cyst group, ( 23 vs. $28.1 \%$, OR 0.826 [95\% Cl $0.46-$ 1.482] $\mathrm{p}$-value $=0.521$ )

\section{Discussion}

As women reproduction is systematically being postponed to later ages, there is a growing number of subfertile patients with less time left. Ovarian cysts are common discoveries in women of reproductive age, especially during ART treatment.

Their physicians are confronted with important fertility questions searching the most appropriate therapeutical strategy for them. While surgery allows a histological diagnostic helping to exclude possible malignant tumors, the ovarian reserve can be reduced after cystectomy, reducing fertility outcomes [17, 19,23]. Furthermore, surgical procedures may critically delay the start of ART treatments in patients who are per se aware of their limited fertility, causing stress and anxiety. On the other hand, a conservative treatment with regular follow-ups, especially in asymptom- atic cases is also possible. The IOTA criteria make it possible to characterize ovarian findings and to estimate the risk of malignancy. On the whole, physicians' dilemma is not easy to solve because surgerys' long-term effect on fertility remains unclear.

How does the presence of ovarian cysts in our sample influence the pregnancy rate? The fertility impact of the cyst depends on its nature, size and number. Endometriomas account for around 35\% of all the persistent benign cysts [28]. Histological analyzes after ovarian cystectomy included $47 \%$ endometriomas, $24 \%$ dermoid cysts, $16 \%$ serous cystadenomas and $13 \%$ mucinous cystadenomas [18]. Similar results were found on previous publications [10]. Therefore, we assume the rate of endometrial cysts present in our sample to be between $35-45 \%$. Cystadenomas are often discovered in women after their reproductive phase.

There is a relationship between endometriosis and infertility [11]. A recent literature review reported that its presence reduces the number of oocytes retrieved and fertilization rates in IVF therapies [21]. Legendre et al. pointed out that it is difficult to determine the influence of endometriomas and endometriosis on fertility [13].

The presence of endometriomas smaller than $4 \mathrm{~cm}$ does not appear to influence the results of ART $[2,3,14,27,30]$. There is a general recommendation to treat only symptomatic endometriomas and/or unilateral endometriomas $>4 \mathrm{~cm}$ [24].

After surgery, AMH level was significantly lower [17], showing a decline in ovarian reserve. The larger the size of endometrioma, the bigger the impact of surgery on the ovarian reserve [16]. The Cochrane meta-analysis by Benschop et al. [5], focused on the management of endometriomas before IVF treatment and reported that surgery did not improve pregnancy rates. The number of oocytes was lower after cystectomy. Also a metaanalysis of Tsoumpou [29] and Garcia-Velasco [9] et al. could not find any benefit of surgery increasing clinical pregnancies.

There are only a few data to non endometriotic cysts. Dermoid cysts are the most common benign finding in the ovaries of young women during their fertility lifespan [12]. One of the studies reported six patients in their sample who had dermoid cysts (as diagnosed by transvaginal ultrasound) while undergoing IVF treatment. All of them achieved similar serum estrogens levels, oocyte retrieval numbers, and gave birth to healthy babies. Despite the small sample size, there is an implication that dermoid cysts do not irreparably affect fertility outcomes [7]. There is no clear recommendation concerning the extirpation of dermoid cysts prior to ART. The risk of dermoid torsion, rupture and malignancy increases with the dermoid size as well as the complexity of the procedure. In non endometriotic cysts, some studies found a postsurgical ovarian damage with decreased ovarian reserve up to $40 \%$ $[8,22]$.

In this retrospective study we focused on a cohort of 550 patients with an asymptomatic incidental ovarian finding before starting an IVF treatment. 328 decided to undergo surgery and 222 preferred a conservative management. Although the lower number of oocytes retrieved after surgery could suggest a negative quantitative effect on the ovary, surgery itself did not impair fertilization rate, pregnancy rate or live birth rate. Comparing this data with a heterogenous notably control group representing an average infertile patient undergoing IVF/ICSI treatment during 
the same period of time, similar pregnancy outcomes were found. We can postulate that surgery does not seem to worsen fertility outcomes as much as the presence of an ovarian cyst does. Our data confirms previous literature [9].

Nevertheless it remains unclear why patients with a remaining cyst showed an apparently lower ovarian responsiveness to hyperstimulation, with higher dosis of gonadotrophin required to obtain the same amount of oocytes and why did they showed relevant lower pregnancy rate and live birth rate than controls. One possible explanation might be a concomitant chronic pelvic inflammation found in non-operated endometriomas inducing infertility and thereby confounding the results [4].

Another explanation could be patients' age, although the difference was not significant. The patients who did not undergo surgery were 1.2 to 1.3 years older than the controls. In an earlier publication [20] we showed that every year the probability of achieving pregnancy reduces $6 \%$.

Some limitations of our study must be taken into consideration. As we did not gather the exact cyst size or histology, we are unable to determine the exact influence of endometriomas discussed above. Regarding the cyst size we assume size bias should bring smaller cysts not to be removed and to increase pregnancy rates, increasing the trend observed in this study. Other limitations are a well-known medical counseling bias and the retrospective cohort design. In order to minimize the confounding elements, we decided to enlarge the cohort. While this did improve our data set, this innacurate control group includes patients with other infertility issues that might affect the results. In our opinion, the control group should represent an average infertile patient attending a fertility center and we do not generate general recommendations.

\section{Conclusion}

There are many aspects involved on fertility patients when ovarian cysts are found, making it difficult to determine the exact impact of ovarian surgery. Counseling physicians rely on guidelines, such as the IOTA criteria, making it possible to estimate the risk of malignancy. Statistics show that endometriomas are the most frequent ovarian masses in patients in their reproductive phase. Presented literature gives no hint if any surgery leads to an improvement on the pregnancy rates. This retrospective analysis together with the current literature might help patients' and physicians decision when ovarian cysts are present before ART procedures.

In symptomatic women, an ovarian cystectomy does not significantly degrade fertility outcomes. Patients considering the procedure should however be carefully advised beforehand about how it could potentially impair their ovarian reserve. Alternatively, asymptomatic women who are older and have lower ovarian reserves are more likely to benefit from more conservative treatment strategies. This approach will not hamper their likelihood of having acceptable outcomes, and deleterious effects on their ovaries will be mitigated.

\section{Conflict of Interest}

The authors declare that they have no conflict of interest.

\section{References}

[1] Chiang AJ, La V, Peng J et al. Squamous cell carcinoma arising from mature cystic teratoma of the ovary. Int J Gynecol Cancer 2011; 21: 466474

[2] Almog B, Sheizaf B, Shalom-Paz E et al. Effects of excision of ovarian endometrioma on the antral follicle count and collected oocytes for in vitro fertilization. Fertil Steril 2010; 94: 2340-2342

[3] Almog B, Wagman I, Bibi G et al. Effects of salpingectomy on ovarian response in controlled ovarian hyperstimulation for in vitro fertilization: a reappraisal. Fertil Steril 2011; 95: 2474-2476

[4] Benaglia L, Pasin R, Somigliana E et al. Unoperated ovarian endometriomas and responsiveness to hyperstimulation. Hum Reprod 2011; 26: 1356-1361

[5] Benschop L, Farquhar C, van der Poel $\mathrm{N}$ et al. Interventions for women with endometrioma prior to assisted reproductive technology. Cochrane Database Syst Rev 2010; (11): CD008571

[6] Borgfeldt C, Andolf E. Transvaginal sonographic ovarian findings in a random sample of women 25-40 years old. Ultrasound Obstet Gynecol 1999; 13: 345-350

[7] Caspi B, Weissman A, Zalel Y et al. Ovarian stimulation and in vitro fertilization in women with mature cystic teratomas. Obstet Gynecol 1998; 92: 979-981

[8] Chang HJ, Han SH, Lee JR et al. Impact of laparoscopic cystectomy on ovarian reserve: serial changes of serum anti-Müllerian hormone levels. Fertil Steril 2010; 94: 343-349

[9] Garcia-Velasco JA, Mahutte NG, Corona J et al. Removal of endometriomas before in vitro fertilization does not improve fertility outcomes: A matched, case-control study. Fertil Steril 2004; 81: 1194-1197

[10] Gerber B, Gustmann G, Külz T et al. [Histology and cytology of laparoscopically operated "simple ovarian cysts"]. Geburtsh Frauenheilk 1995; 55: 369-373

[11] Juhasz-Böss I, Laschke MW, Müller F et al. Endometriosis: Survey of Current Diagnostic and Therapeutic Options and Latest Research Work. Geburtsh Frauenheilk 2014; 74: 733-742

[12] Kahraman K, Çetinkaya ŞE, Kankaya D et al. Squamous cell carcinoma arising from mature cystic teratoma of the ovary with synchronous endometrial adenocarcinoma. J Obstet Gynaecol Res 2011; 37: 146-150

[13] Legendre G, Catala L, Moriniere C et al. Relationship between ovarian cysts and infertility: what surgery and when? Fertil Steril 2014; 101: 608-614

[14] Maignien C, Santulli P, Gayet V et al. Prognostic factors for assisted reproductive technology in women with endometriosis-related infertility. Am J Obstet Gynecol 2017; 216: 280

[15] Nunes N, Ambler G, Foo X et al. Use of IOTA simple rules for diagnosis of ovarian cancer: meta-analysis. Ultrasound Obstet Gynecol 2014; 44: 503-514

[16] Prefumo F, Rossi AC. Endometriosis, endometrioma, and ART results: Current understanding and recommended practices. Best Pract Res Clin Obstet Gynaecol 2018; 51: 34-40. doi:10.1016/j.bpobgyn.2018.01.019

[17] Raffi F, Metwally M, Amer S. The impact of excision of ovarian endometrioma on ovarian reserve: A systematic review and meta-analysis. J Clin Endocrinol Metab 2012; 97: 3146-3154

[18] Retto G, Santoro G, Sturlese E et al. Efficacy of laparoscopic stripping for ovarian cysts: histological and clinical findings. J Obstet Gynaecol Res 2011; 37: 547-552

[19] Rimbach S, Ulrich U, Schweppe KW. Surgical therapy of endometriosis: Challenges and controversies. Geburtsh Frauenheilk 2013; 73: 918-923

[20] Schorsch M, Gomez R, Hahn T et al. Success Rate of Inseminations Dependent on Maternal Age? An Analysis of 4246 Insemination Cycles. Geburtsh Frauenheilk 2013; 73: 808-811 
[21] Sanchez AM, Vanni VS, Bartiromo L et al. Is the oocyte quality affected by endometriosis? A review of the literature. J Ovarian Res 2017; 10: 4347

[22] Somigliana E, Ragni G, Infantino M et al. Does laparoscopic removal of nonendometriotic benign ovarian cysts affect ovarian reserve? Acta Obstet Gynecol Scand 2006; 85: 74-77

[23] Somigliana E, Berlanda N, Benaglia L et al. Surgical excision of endometriomas and ovarian reserve: A systematic review on serum antimüllerian hormone level modifications. Fertil Steril 2012; 98: 1531-1538

[24] Soriano D, Adler I, Bouaziz J et al. Fertility outcome of laparoscopic treatment in patients with severe endometriosis and repeated in vitro fertilization failures. Fertil Steril 2016; 106: 1264-1269

[25] Surrey ES. Endometriosis-Related Infertility: The Role of the Assisted Reproductive Technologies. Biomed Res Int 2015; 2015: 482959
[26] Timmerman D, Valentin L, Bourne TH et al.; International Ovarian Tumor Analysis (IOTA) Group. Terms, definitions and measurements to describe the sonographic features of adnexal tumors: a consensus opinion from the International Ovarian Tumor Analysis (IOTA) Group. Ultrasound Obstet Gynecol 2000; 16: 500-505

[27] Tocci A, Lucchini C, Minasi MG et al. Unilateral ovarian endometriotic cysts do not impair follicles development, oocyte and embryo quality: report on eight controlled ovarian hyperstimulations and ICSI cycles. Hum Reprod 2010; 25: 288-289

[28] Tsolakidis D, Pados G, Vavilis D et al. The impact on ovarian reserve after laparoscopic ovarian cystectomy versus three-stage management in patients with endometriomas: a prospective randomized study. Fertil Steril 2010; 94: 71-77

[29] Tsoumpou I, Kyrgiou M, Gelbaya TA et al. The effect of surgical treatment for endometrioma on in vitro fertilization outcomes: a systematic review and meta-analysis. Fertil Steril 2009; 92: 75-87

[30] Yang C, Geng Y, Li Y et al. Impact of ovarian endometrioma on ovarian responsiveness and IVF: a systematic review and meta-analysis. Reprod Biomed Online 2015; 31: 9-19 